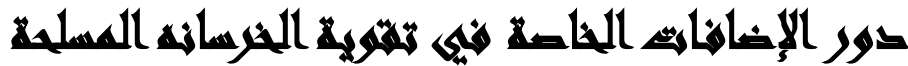

\section{$[1 \cdot]$}

\author{
أبجاد محمد البصيري
}

الهيئة العامة للتعليم التطبيقي والتدريب دولة الكويتز

\section{المستخليه}

تهاف الدراسة إلى التعرف على دور الإضافات الخاصة في تقوية الخرسانة المسلحة

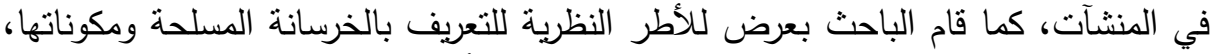

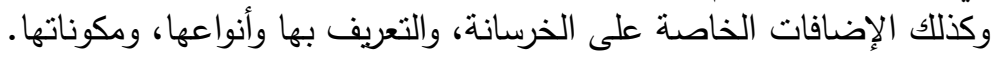

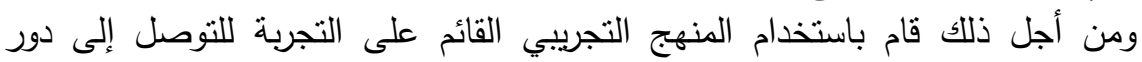
الإضافة الخاصة على الخرسانة المسلحة في تقويتها، وقام الباحث بعمل تجرية باتجة باستخدام (CF/ACC) وتوصلت نتائج الاراسة إلى الآتي:

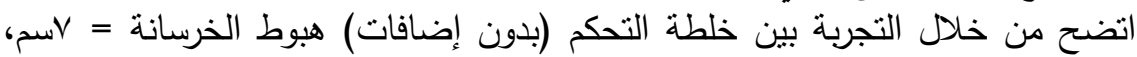

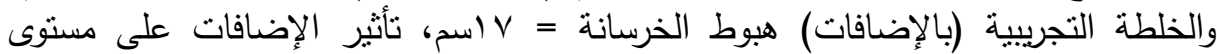

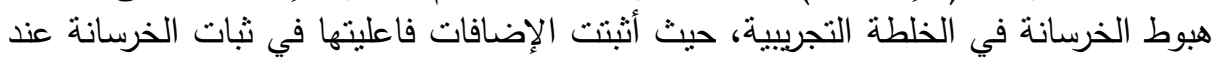

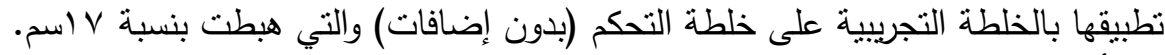
كما أوصت الدراسة بالاتي:

• ضرورة استخدام الاضافات للخرسانة لما لها من دور فاعل في تقوية الخرسانة المسلحة.

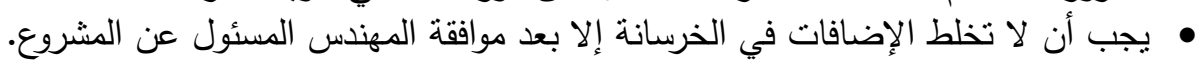
• • • • •

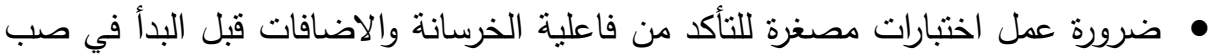

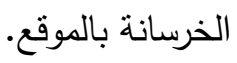

\section{هos}

يعتبر الرومان هم أول من استعملوا الخرسانه العاديه Concrete في التاريخ من حوالي

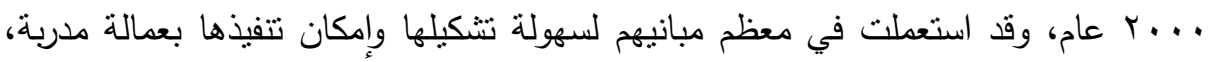
حيث أثنتت نجاح باهر في العديد من المواقع والمباني القديمة، مثل: مبنى البانثيون في روما، 
(C. L. Page \& M. وقناطر بونت دور جارد ... إلخ، والتي لا تزال قائمة حتى وقتتا هذا M. Page, 2007, p.1) والخرسانة مخلوط من مواد أولية مكون من الرمل والزلط (أو كسر الأحجار)، والأسمنت

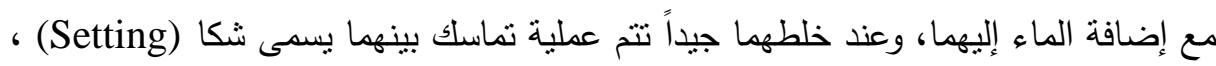

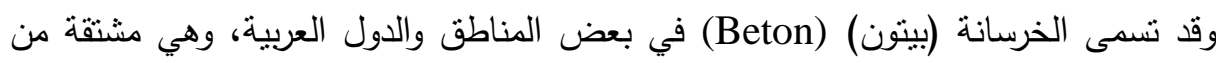
أسم الخرسانة باللغة الفرنسية.

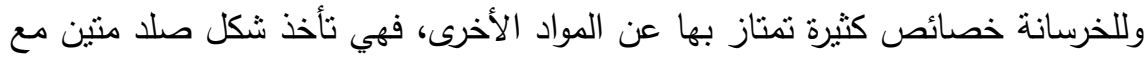
الزمن تدريجياً، وتبدأ بالثك الابتدائي (Initial Setting) ثم الثك النهائي بهائي (Final) Setting) كذلك فهي جيدة المقاومة للضغط (Compression) ، وفي نفس الوقت ضعيفة

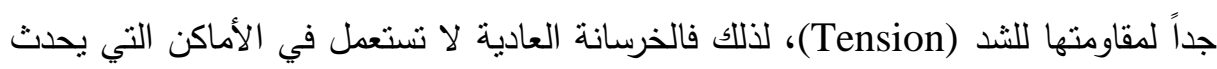

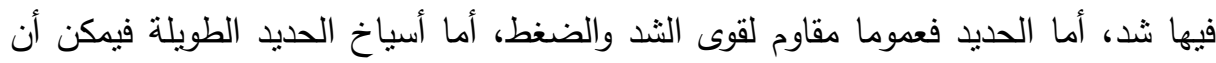

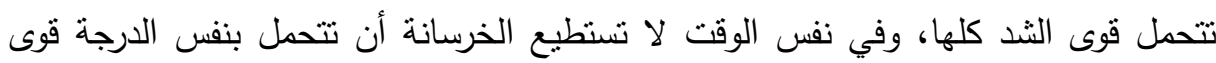
الضغط كلها نتيجة إنبعاجها (Buckling) الذي قد يحدث للخرسانة المسلحة إذا كانت قطاعاتها نحيفه (Selinderness) ، وعلى ذلك نجد أن مركب من مواد الخرسانة والحديد

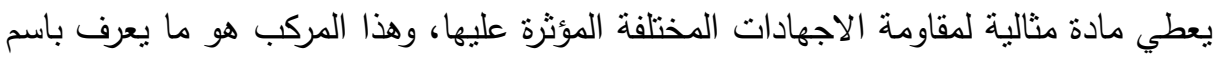

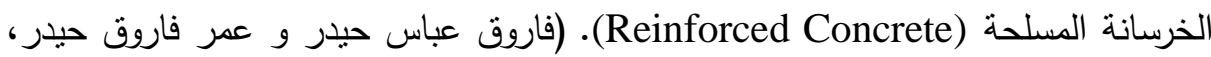
$($ r $\Lambda:$ Y.) وتحتاج الخرسانة إلى بعض الإضافات لتعطي خصائص خاصة تساعد في تتفيذ

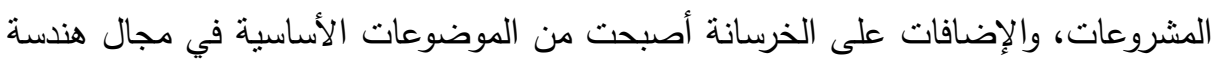

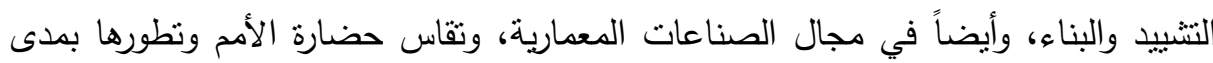
استخدامها لهذه الإضافات الحديثة حيث إن هذه المواد تزيد من العمر الافتراضي للمنشآت

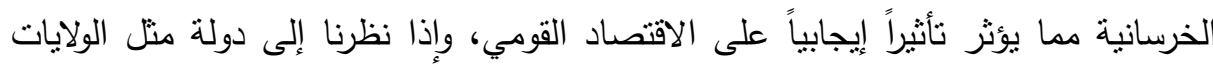

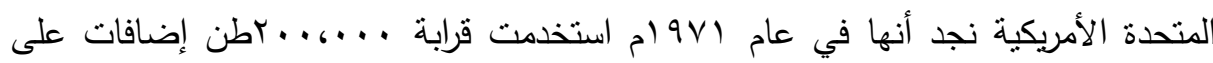

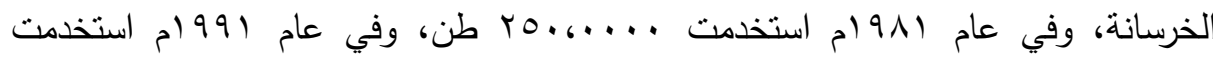

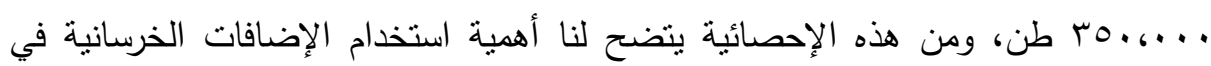
176

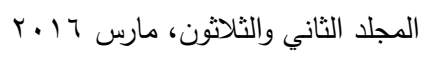




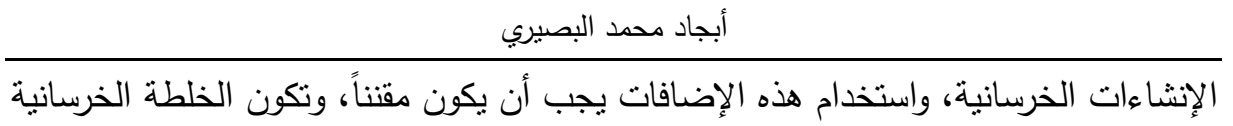
المستخدمة بها الإضافة مصممة، وأن يكون لها خلطة محسوبة ومعايرة طبقاً للمواصفات.

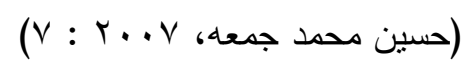

والمواد المضافة هي عبارة عن مواد وتراكيب تضاف للخرسانة أثناء الخلط لتحسين خاصية أو أكثر من خواص الخلطة الخرسانية، وإكسابها ميزات جديدة تتتاسب مع الأغراض فئراف والمنطلبات لها سواء كان تجهيزها بواسطة محطات الخلط المركزي أو بالموقع، والمواد المضافة للخرسانة هي التي تكون خلاف مكونات الخلطة الخرسانية المكونة من ماء وأسمنت

$$
\text { وركام لإعطائها خواص مطلوبة في ظروف العمل. }
$$

وللإضافات الخرسانية استخدامات عديدة سواء كان استخدامها في عمليات الخلط

بالموقع أو في محطات الخلط المركزية أو في مصانع الخرسانة الجاهزة أو الخرسانية سابقة

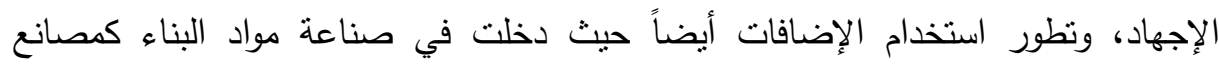

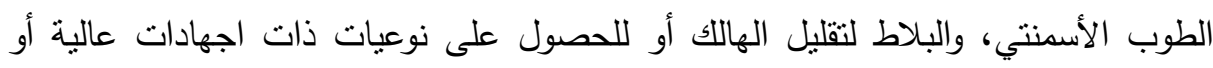
للوفاء بالطلبات السريعة حيث يتم استخدام الإضافات الخاصة بالحصول على اجهادات مبكرة

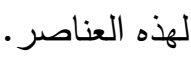
تعريف الخرسانة (Concrete): الخرسانة هي بنيان Structure ينركب من عدة مواد

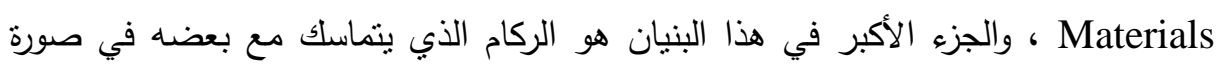

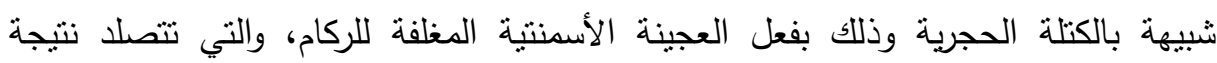

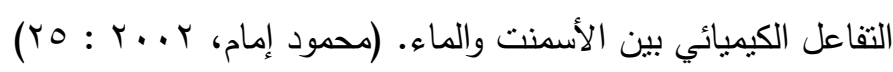

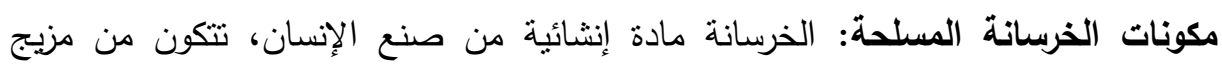
متجانس تقريباً من جسيمات حبييية صلدة منتوعة المقاسات، تعرف بالركام (Aggregate) تشغل نسبة كبيرة من حجم المادة، يتم تثبيتها بهيكل رابط ولاصق من من معجون الأسمنت المتصلد بفعل الماء، والخرسانة في حالتها المتصلدة تبدو كمادة صخرية ذات مقاومة عالية

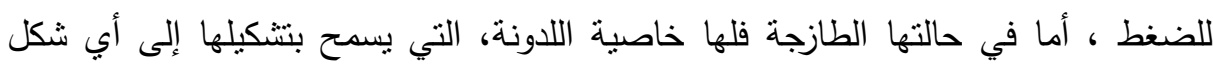

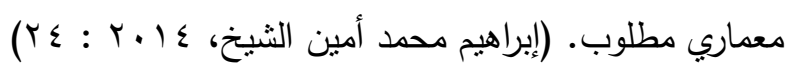


والخرسانة العادية مقاومتها ضعيفة نسبياً للثد (Tension) حيث يتراوح تحمل الخرسانة للثد بين (1-1/\%) من تحملها للضغط، وتوجد طرق دقيقة لقياس تحمل الثد

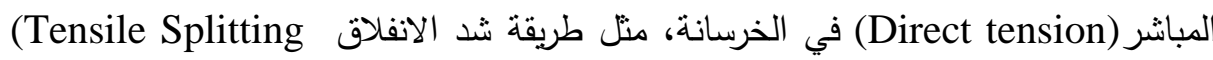

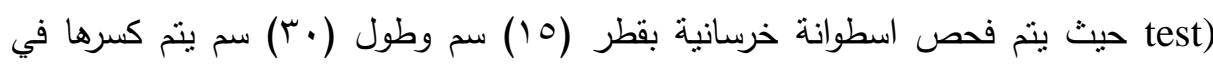
جهاز اختبار الضغط، بتأثير قوة ضغط عليها، عندما يكون محورها الطولي بوضع أفقي،

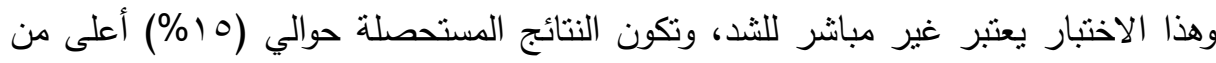

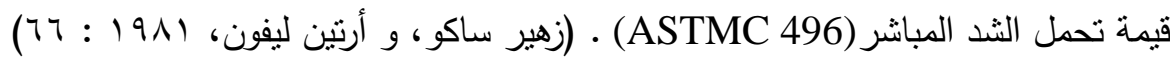

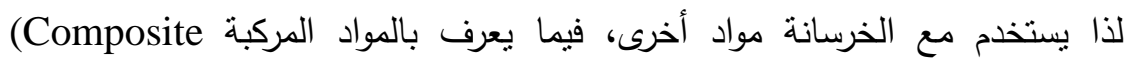
Materials)

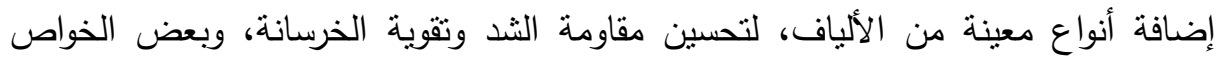
الميكانيكية الأخرى، والخرسانة الجيدة تحتاج إلى صيانة قلبلة، كما أنها مقاومة جيدة للحريق،

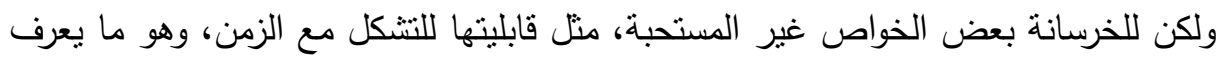
بالزحف، إلا أنه إذا أخذ في الاعتبار في مرحلة التصميم تأثير كل الظروف البيئية المحيطة

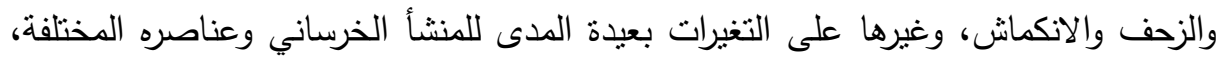

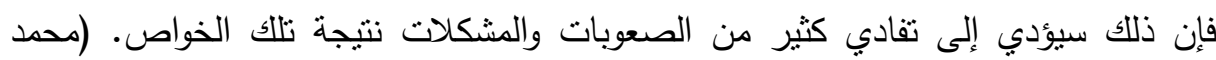

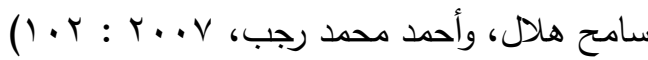

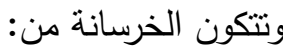
أولاً: المواد الأساسية، وهي: الخئة هن: الأسمنت، والركام، والماء.

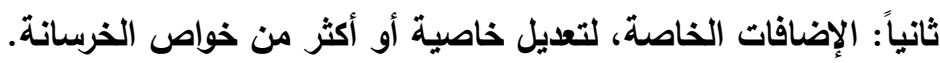
المحور الأول: المواد الأساسية، وهي على النحو التالي:

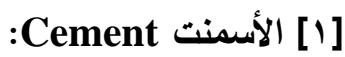

كل أنواع الأسمنتات المستخدمة في الخرسانة تكون مطحونة إلى درجة نعومة عالية، ولكنها تختلف حسب نوع الأسمنت المنتج، ولها خاصية التفاعل مع الماء (الإماهة)، والتي ينتج عنها -بمرور الوقت - مادة لاحمة لحبييات الركام، صلدة وقوية، تزيد قوتها ومقاومتها 


\section{أبجاد محمد البصيري}

للأحمال مع الزمن، ويحتوي الأسمنت البورتلاندي العادي (الثائع الاستخدام عالمياً) في النياد الخرسانة على أربعة مركبات أساسية، وهي سليكات ثلاث وثنائي الكالسيوم، وألومينات ثلاثي الاني

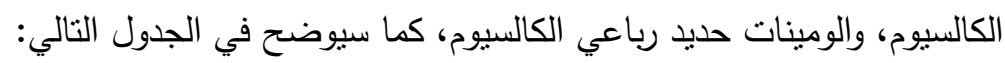

(H. F. W. Taylor, 1997 : 2-5)

\begin{tabular}{|c|c|c|}
\hline الاختصار العلمي & التركيب الكيميائي & اسم المركب \\
\hline $\mathrm{C}_{3} \mathrm{~S}$ & $3 \mathrm{CaO} \cdot \mathrm{siO}_{2}$ & سليكات ثلاتي الكالسيوم \\
\hline $\mathrm{C}_{2} \mathrm{~S}$ & $2 \mathrm{CaO} \cdot \mathrm{sio}_{2}$ & سليكات ثثائي الكالسيوم \\
\hline $\mathrm{C}_{3} \mathrm{~A}$ & $3 \mathrm{CaO} . \mathrm{AL}_{2} \mathrm{O}_{3}$ & ألومينات ثنائي الكالسيوم \\
\hline $\mathrm{C}_{4} \mathrm{AF}$ & $4 \mathrm{CaO} \cdot \mathrm{AL}_{2} \mathrm{O}_{3} \cdot \mathrm{fe}_{2} \mathrm{O}_{3}$ & ألومينات حديد رباعي الكالسيوم \\
\hline
\end{tabular}

ويتضح من الجدول السابق دقة الضبط والمعايرة أثناء عمليات نوزيع المكونات بشكل

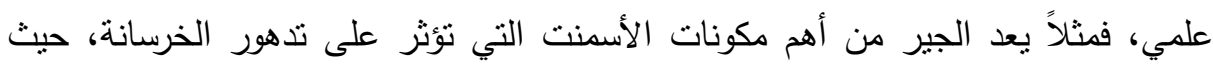

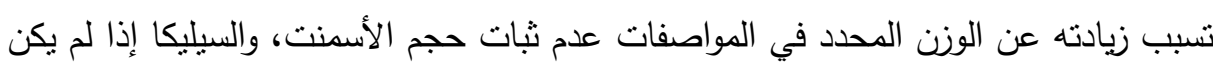
توزيعها جيداً بين المكونات، فتكون النتيجة أسمنت غير ثابت وضنيف وضعيف، وذللك لعدم اكتمال

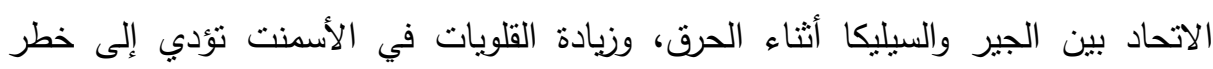

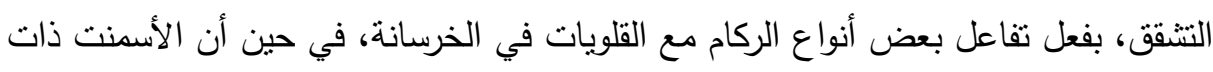

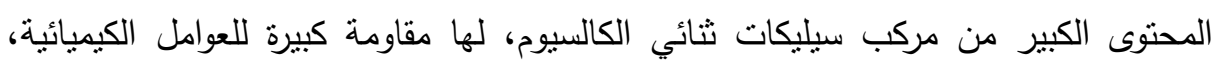

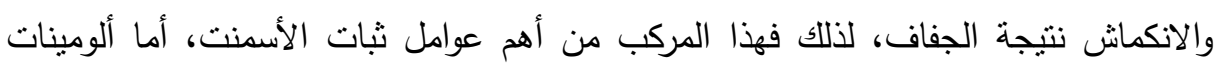

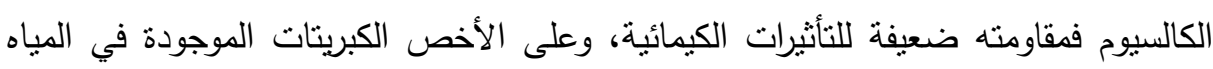

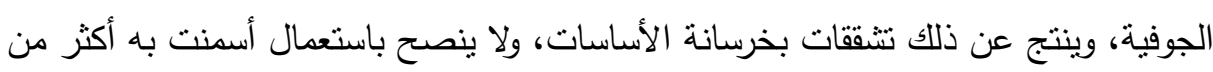

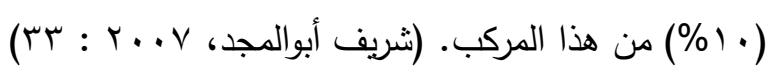

والأسمنت هو المكون الرئيس الفعال الذي تتوقف عليه مقاومة الخرسانة، وأهم العوامل

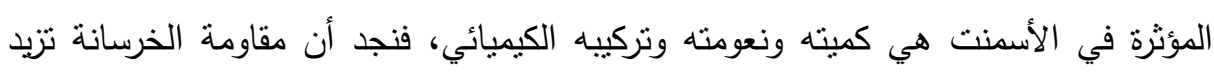
بزيادة محتوى الأسمنت، وذلك حتى محتوى معين يقل عنده معدل الزيادة في المقاومة ثم تتوقف الزيادة في المقاومة بعد ذلك وربما تقل، وهذا المحتوى يختلف باختلاف نسب ودئ مكونات

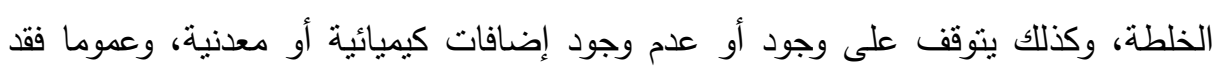

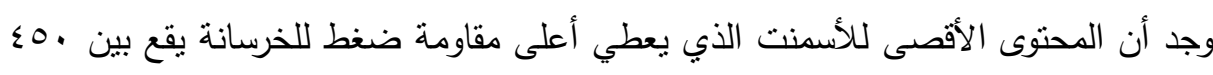

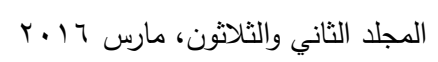


و ،00 كج/ج ب ، أما بالنسبة لنعومة الأسمنت فهي تؤثر تأثيراً كبيراً على مقاومة الخرسانة وخاصة في الأعمار المبكرة حتى بـ ب يوم، بعد ذللك يقل معدل الزيادة في المقاومة تدريجياً

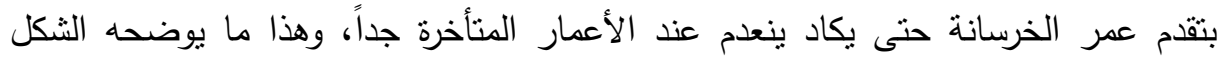

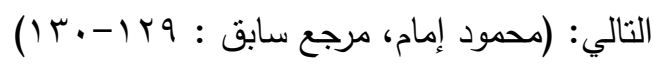
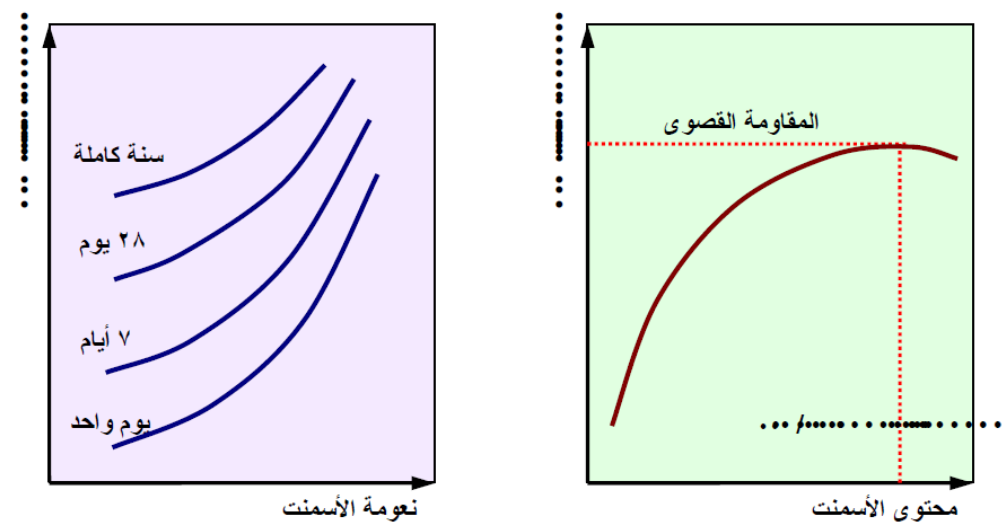

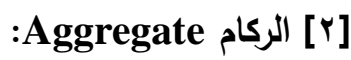

يتكون الركام من مجموعة من جسيمات ذات مقاسات متباينة، وتكون مادة صلدة

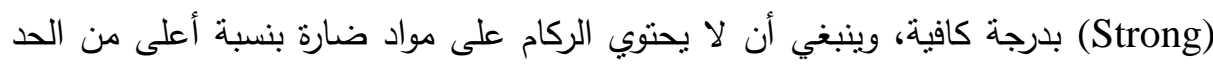

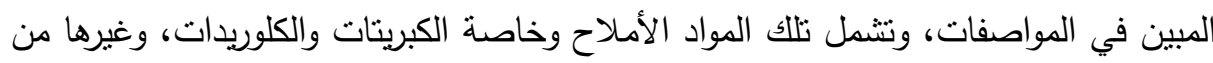

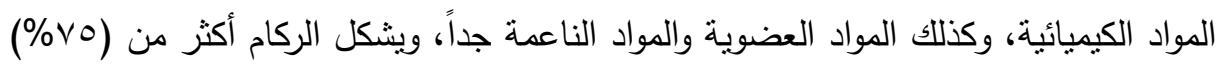

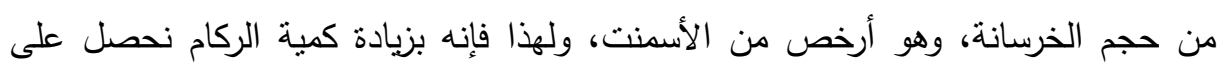

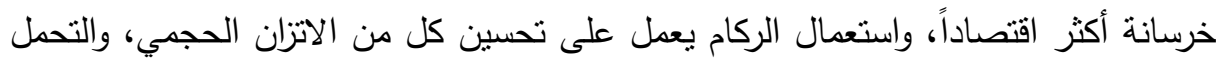

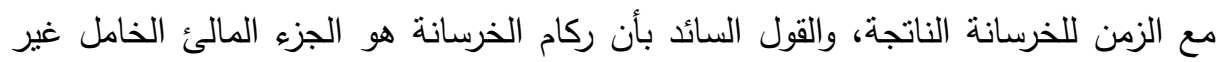
دقيق التعبير، حيث إن خواصد الطبيعية، وأحياناً كثيرة الكيمائية في بعض النهان الأحيان، تؤثثر

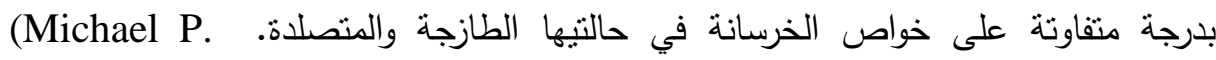
Edison, 2008 : 75-76)

ومن أهم خواص الركام المؤثرة على تدهور الخرسانة، هي المسامية أو الفراغات داخل

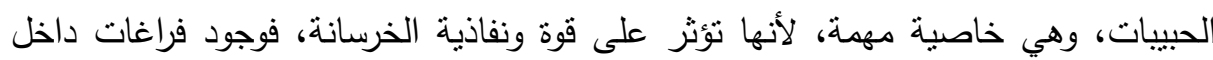


حبيبات الركام يضعفها، وفي نفس الوقت يزيد من قدرة الركام على امتصاص الماء والنفاذية

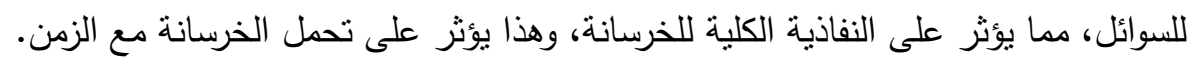

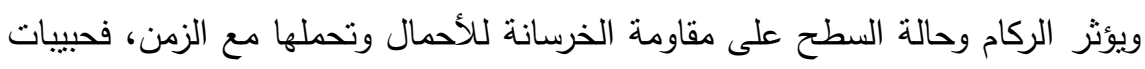

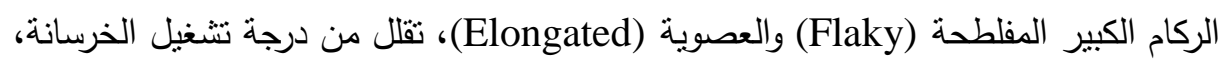

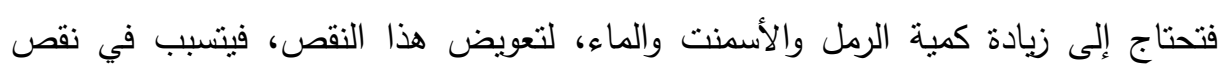
مقاومة الخرسانة للضغط، ويؤثر شكل وحالة الركام الصغير على كمية الماء المطلوبة

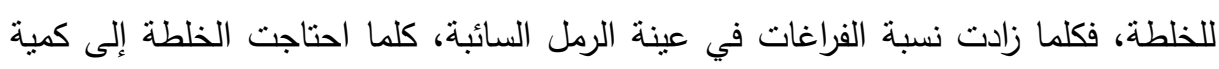

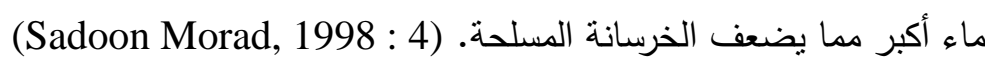

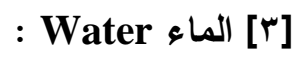

ويستخدم الماء في الخلطات الخرسانية بنسب معيارية محددة ومدروسة، ويجب أن يكون

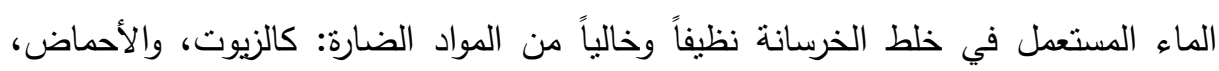

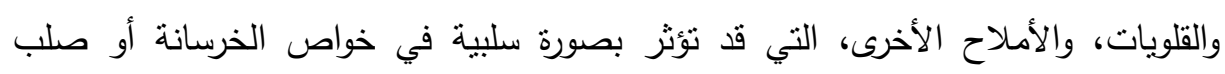

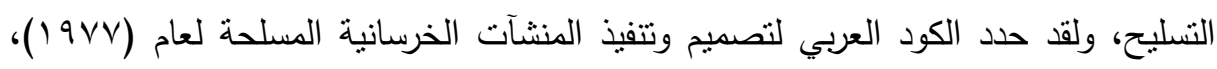

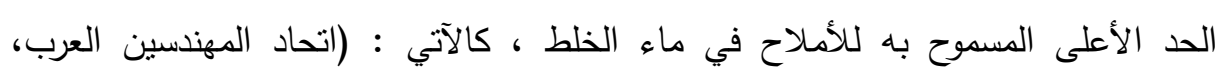
(I): I $9 \vee V$

$$
\begin{aligned}
& \text { • أملاح الكلوريدات لا تزيد عن } 0.5 \text { غم / لتر • } \\
& \text { • أملاح الكبريتات لا تزيد على } 0.3 \text { غم / لتز • }
\end{aligned}
$$

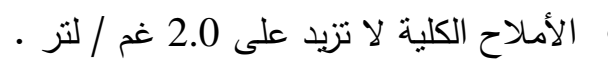

واعتبر الماء الصالح للشرب مناسباً في جميع الأحوال لخلط الخرسانة لإنة إلا أنه يمكن

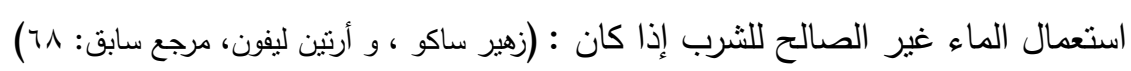

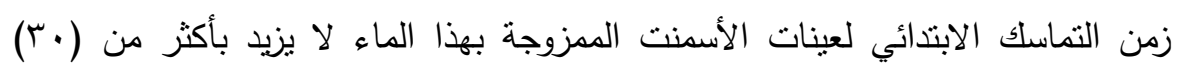

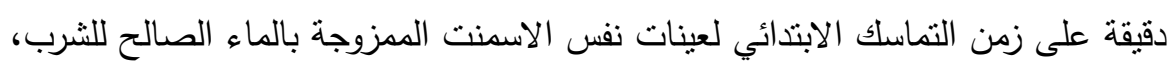

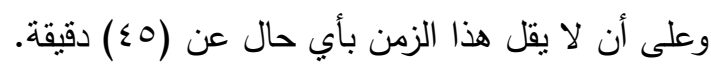

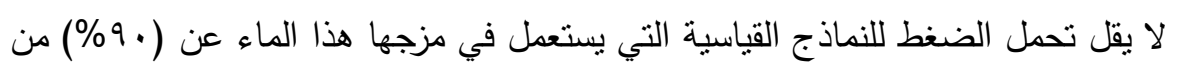

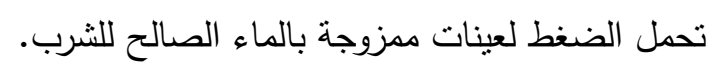

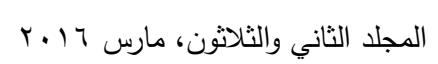


ولا يجوز استعمال ماء البحر في إنتاج الخرسانة المسلحة، إلا أنه قد يستعمل عند

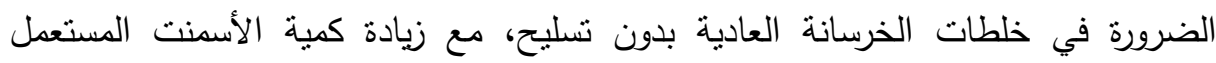

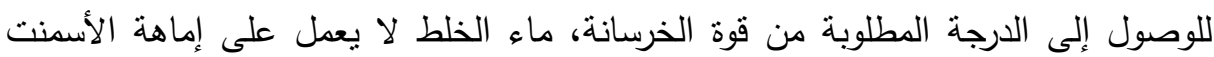

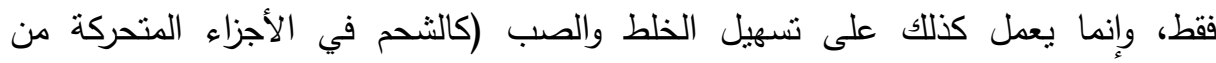
الماكينات) والثوائب التي لها تأثنير ضار على الخرسانة، نتشل الطفلة والطين والأحماض ومياه المجاري، ويجب أن لا تزيد نسب تركيز هذه الثوائب عن تلك المبينة في الجدول

التالي: (Mindess, S. \& Young, J. F., 1981: 142)

جدول يوضح المستويات المسموح بها للشوائب في ماء الخلط بالخرسانة المسلحة

\begin{tabular}{|c|c|c|}
\hline 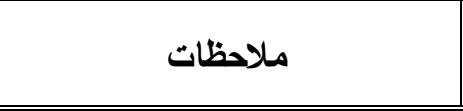 & الحد الأقصى للتركيز & الشوائب \\
\hline طفلة، طين، مواد عضوية & r... & مواد عالقة \\
\hline تقلل وقت التصلد & $1 \ldots$ & الكربونات \\
\hline \multirow{3}{*}{ 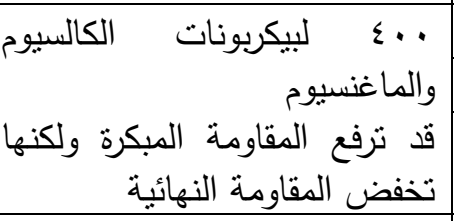 } & $1 \ldots-\varepsilon \ldots$ & بيكربونات \\
\hline & $1 \ldots$ & كبريتات الصوديوم \\
\hline & $\varepsilon \cdots$ & كبريتات الماغنسيوم \\
\hline \multirow{3}{*}{ النهائية } & $r \ldots$ & كلوريد الصوديوم \\
\hline & $0 \ldots$ & كلوريد الكالسيوم \\
\hline & $\varepsilon \ldots$ & كلوريد الماغنسيوم \\
\hline تؤخر الثكك & $0 .$. & الفوسفات وأملاح الزنكك والنحاس \\
\hline \multirow[t]{2}{*}{ الأس الهيدروجيني أقل من r } & $1 \ldots$ & الأحماض غير العضوية \\
\hline & $0 .$. & هيدروكسيد الصوديوم \\
\hline يجب اختيار الخرسانة & $1 \ldots$ & كبريتيد الصوديوم \\
\hline يؤخر الثك & $0 .$. & 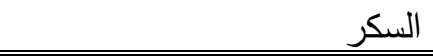 \\
\hline
\end{tabular}




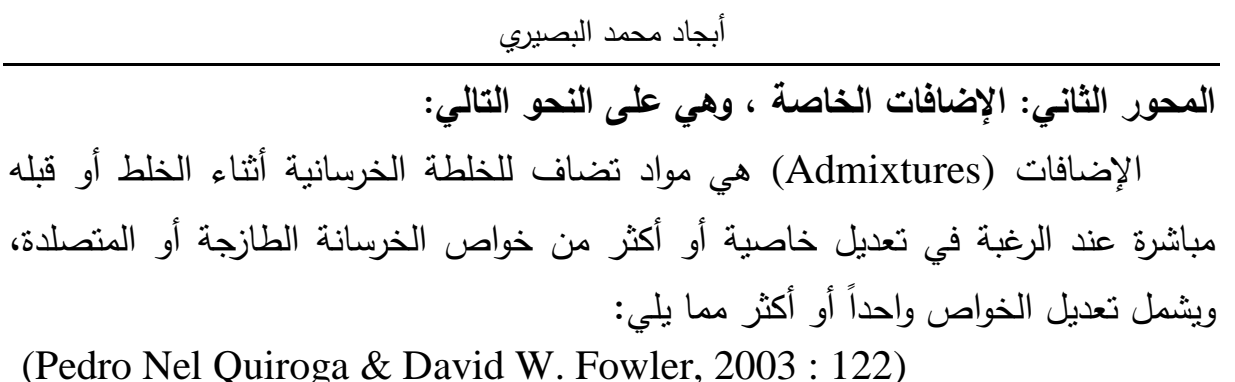

• تحسين قابلية تتغيل الخرسانة الطازجة (Workability). • • • • • • إنقاص كمية الماء الممكن استعمالها في الخلطة.

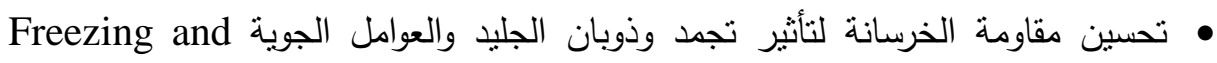
.thawing

$$
\begin{aligned}
& \text { • • تعجيل أو إبطاء التماسك و / أو التصلد. }
\end{aligned}
$$

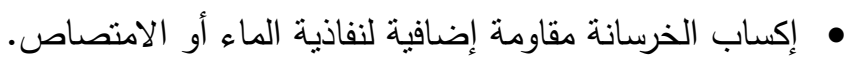

$$
\begin{aligned}
& \text { • زيادة مقاومة سطح الخرسانة لتأثثر التآكل بالاحتكاك (Wear Resistance). }
\end{aligned}
$$

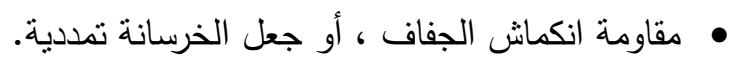

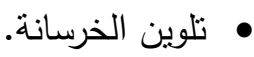$$
\text { • إيقاف أو إنقاص تفاعلات كيميائية ضارة. }
$$$$
\text { • تقليل نزف الماء في الخرسانة الطازجة. }
$$$$
\text { • تقليل حرارة التفاعل (الإماهة) أو إبطاء انطلاقها. }
$$

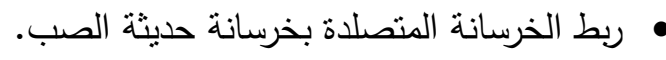$$
\text { وتتعدد الإضافات الخاصة للخرسانة المسلحة، ومنها: }
$$$$
\text { أنواع الإضافات الخاصة بالخرسانة المسلحة: }
$$

[1] [إفافات لزيادة القابلية للتشغيل Wedro Nel Quiroga \& David :Workability

W. Fowler, 2003 : 122)

والغرض من استخدام هذه الإضافة هو سهولة نقل الخرسانة، وسهولة صبها في الفرم

دون حدوث انفصال لحبيباتها، وهذا يساعد بالتالي على عدم حدوث تعشيش بالخرسانة، وما

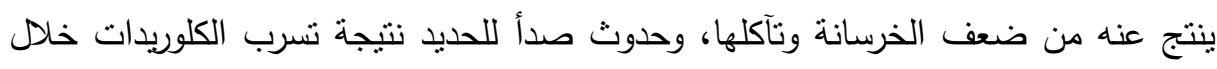
مسام التعشيش.

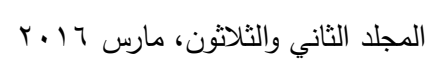


وتنقسم المواد والإضافات من هذا النوع إلى قسمين: أ- المواد البودرة التي تضاف للخرسانة لزيادة قابلية التشغيل: وهي الطريقة القديمة حيث يتم طحن بعض المواد مثل الكاولين أو الجير المطفي أو الخبث المطحون، ويتم الطحن وهن

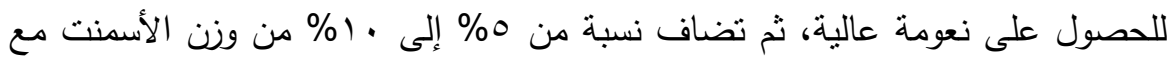

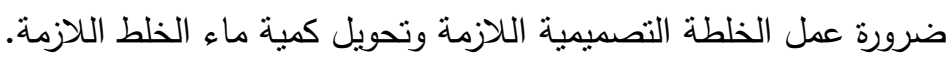

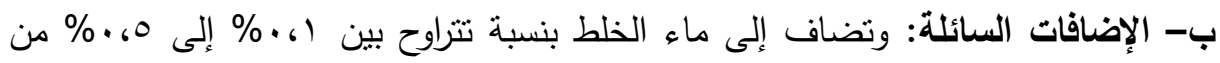

الأسمنت وحسب الخلطة التصميمية.

درجات القابلية للتشغيل وعامل الدمك المقابل لها

\begin{tabular}{|c|c|c|c|}
\hline استخدامات الخرسانة & عامل الدمك & الهبوط (مم) & للتشة القابلية \\
\hline خابقة الصبة للطرق مدموكة بالاهنتام - الكمرات السكات &. ، $10-.6 \vee \wedge$ & صفر - r. & منخفضة جداً \\
\hline 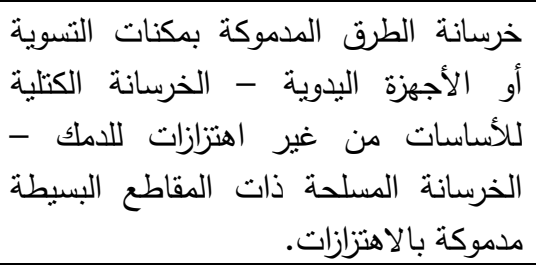 & $.69 Y-.610$ & $0 .-Y$. & منخفضة \\
\hline 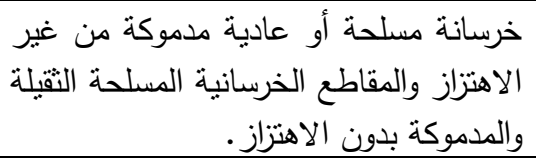 & $.690-.694$ & vo-o. & $\begin{array}{c}\text { متوسطة } \\
\text { Medium }\end{array}$ \\
\hline 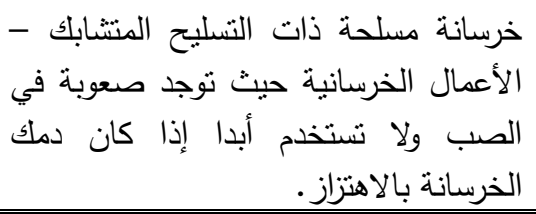 & أكثر من 90، . & $1 \ldots-v_{0}$ & $\begin{array}{c}\text { عالية } \\
\text { High }\end{array}$ \\
\hline
\end{tabular}


أبجاد محمد البصبري

[r] [بإضات الهواء المحبوس Air Entraining تعنبر إضافات الهواء المحبوس من أحدث الإضافات حيث إن الخرسانة المصممة

$$
\begin{aligned}
& \text { بإنتاج الهواء المحبوس بداخلها تعطيها الخواص الآتية: } \\
& \text { • مقاومة عالية للعوامل الجوية والجليد. } \\
& \text { • زيادة قابلية التشغيل. } \\
& \text { • زيادة التحمل مع مرور الوقت. } \\
& \text { • •قليل الإنفصال الحبيبي. }
\end{aligned}
$$

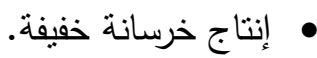

$$
\begin{aligned}
& \text { • • تقليل ماء الخلط. }
\end{aligned}
$$

ويستخدم هذا النوع من الإضافات في خرسانة الطرق في المناطق الباردة، وفي المنشآت

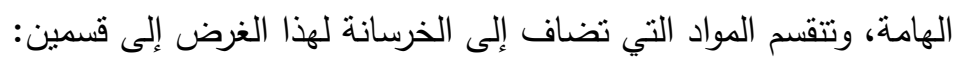

[أ] مواد تضاف لإحداث رغاوي : وهي مواد تضاف أثناء الخلط فتحدث رغاوي مثل الراتتجات

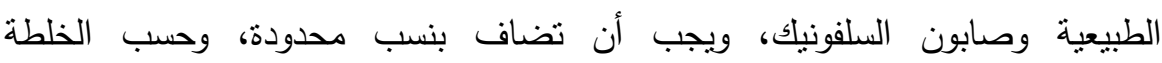

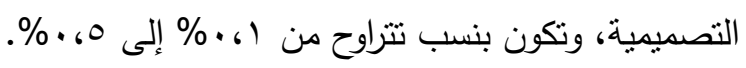

[ب] مواد تضاف لإحداث غاز وفقاعات GAS : وهي مواد تحدث غاز منل غاز الهيدروجين

$$
\text { منل مسحوق الزنك والألومنيوم. }
$$

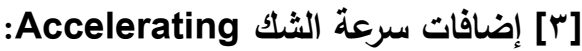

(Sommer, H., Nixon, P.J. \& Sims, I., 2005: 787-792)

وهي إضافات تقلل زمن الثنك، وتزيد من تصلا الخرسانة، وبالتالي تسرع من الثنك،

$$
\text { وهذه الإضافات لها المميزات التالية: }
$$

$$
\text { • فلك الحصول على مقاومة مبكرة للخرسانة. }
$$

م تقليل المعالجة للخرسانة.

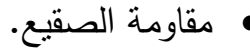

ومن أثنر المواد المستخدمة في ذلك هيدروكلوريد الكالسيوم، ولكن ينصح بعد استخدام

الإضافات المحتوية على ذلك الكلوريد لما يسببه من أضرار كثيرة على حديد التسليح، ويوجد

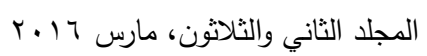


مواد أخرى لهذا الغرض من المركبات العضوية أو السليكات، ويجب أن تكون النسب مدروسة جيداً، حسب زمن الثثك المطلوب مع عمل الخلطات التصميمة اللازمة وأخذ الاحتياطات الكافية أنثاء الصب مثل تغطية الخرسانة في الأجواء الحارة لتجنب التصلا قبل الوقت

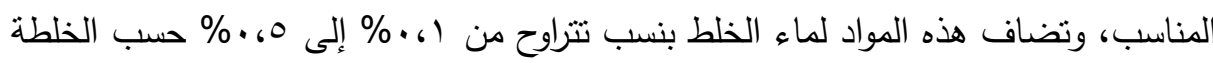

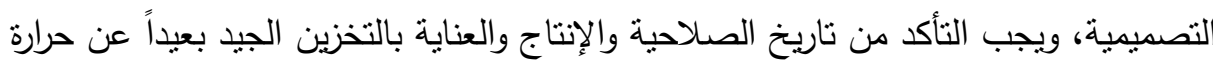

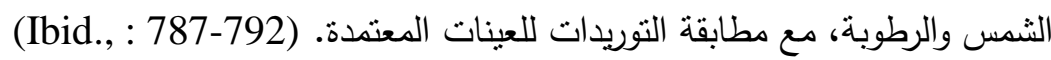

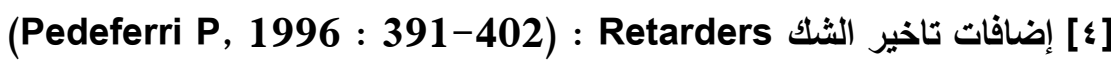
تقوم المادة بتأخير شك الأسمنت، أي تزيد من زمن شك الأسمنت، وتصلد الخرسانة،

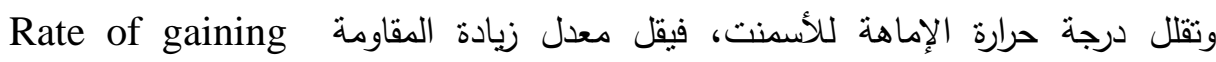

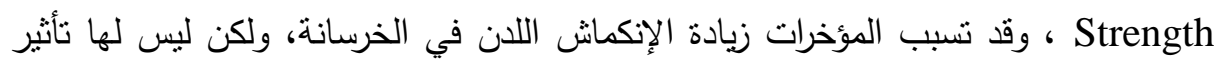
يذكر على الخواص الطبيعية والميكانيكية للخرسانة المتصلدة. وتستخدم الإضافة في عربات خلط الخرسانة وصب آبار البترول حيث تكون الأعماق

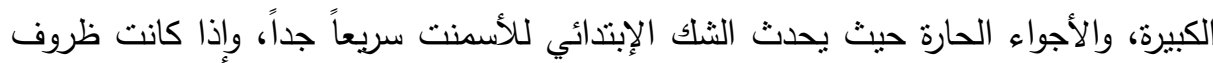

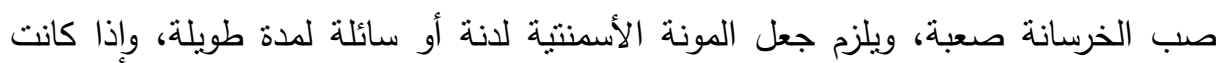

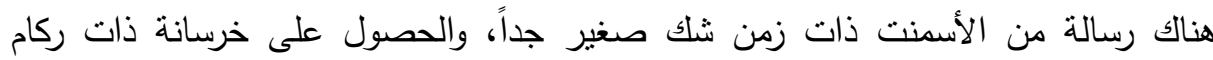

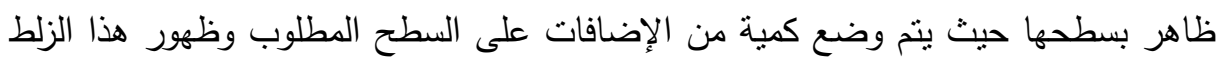

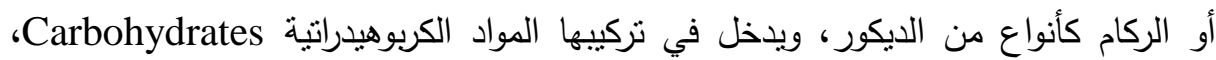

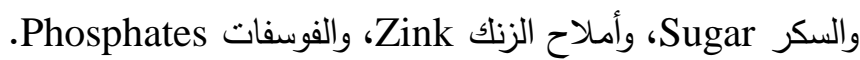

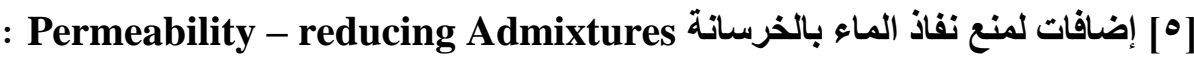
(Brooks J J \& Al-Quarra H, 1999 : 21-26)

تساعد المادة على عدم أو تقليل نفاذ الماء إلى الخرسانة، ولكنها لا نمنع نفاذ الماء تماماً، وللوصول إلى درجة عالية من مقاومة النفاذية ينبغي العناية بتصميم الخلطة الخرسانية ثم العناية بعمليتي الدمك والمعالجة. ويمكن من خلالها تحسين منففية الخرسانة من خلال الآتي: 
أبجاد محمد البصيري

• إضافة صادة للماء (Water Proofing Agents): وهي تعمل على منع الخرسانة

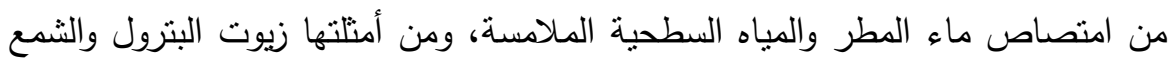

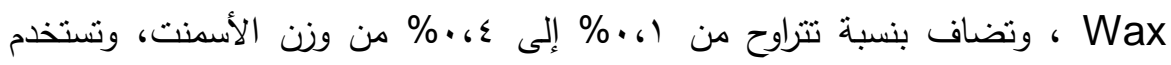

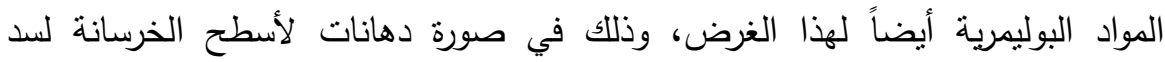
الفجوات الهوائية والثروخ الثعرية الموجودة بالسطح.

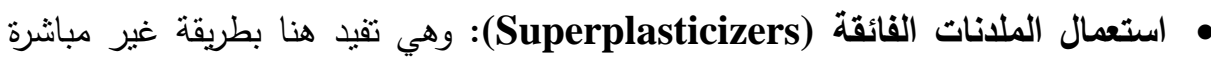
حيث إنها تعمل على تقليل ماء الخلط، وبالتالي الحصول على أقل نسبة فراغات ممكنة بالخلطة، ومن ثم تتحسن منفذية الخرسانة.

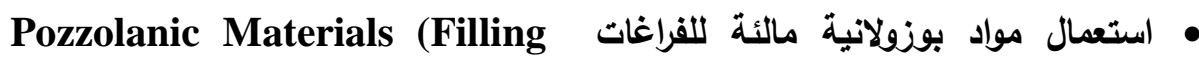

(Effect) الناتج من تفاعل الأسمنت مع الماء مكونة مركبات غير قابلة للذوبان منل سليكيات

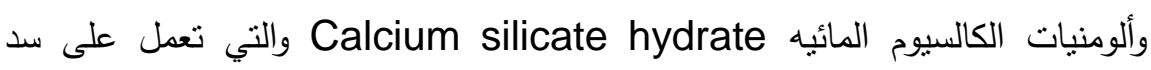
الفجوات الداخلية والمسام الشعرية ومن أمتلتها مادة غبار السيليكا Silica Fume وهي مادة تتكون من حبييات دقيقة جداً مساحتها السطحية حوالي أربعة إلى خمسة أمثال

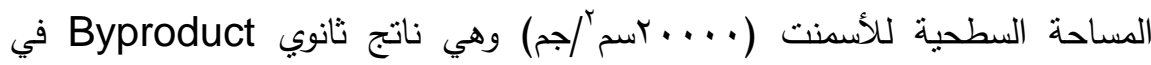
صناعة سبائك السيليكون والفيروسليكون، وتتفاعل مادة غبار السيليكا مع هيدروكسيد

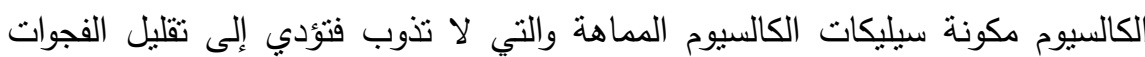

الداخلية والمسام الثعرية. (Ibid, 21-26) ويوضح الباحث في السطور التالية أمثلة لبعض المواد من حيث تركيبها الكيميائي

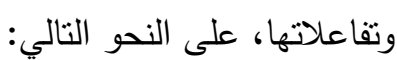

(1) مادة كيم فلو سوير Prakem, 2014 : 55) CF/ACC تعتبر مادة كيم فلوسوبر من المواد الهامه للخرسانه، حيث تضاف للخرسانه لتقليل

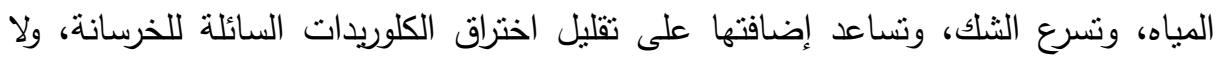
تحتوي على القلويات لاسراع الثك، وتقليل نسبة المياه للأسمنت، مع رفع الاجهادات المبكرة

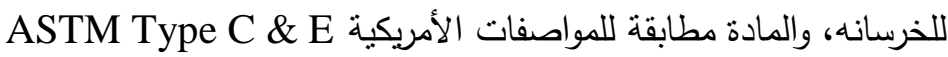

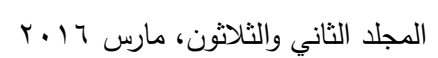


ومن مواصفاتها الفنية أنها عديمة اللون، ودرجة الغليان 100م ، ونسبة الكلوريدات بها

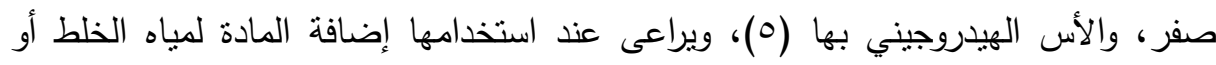

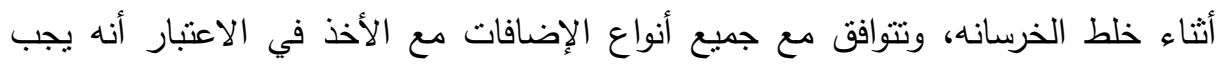

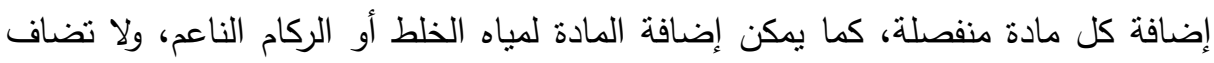
المادة للأسمنت أو المواد البوزولانية.

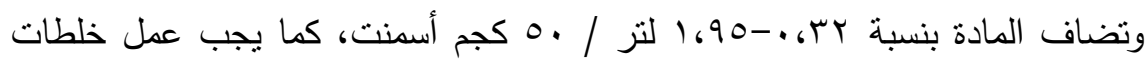

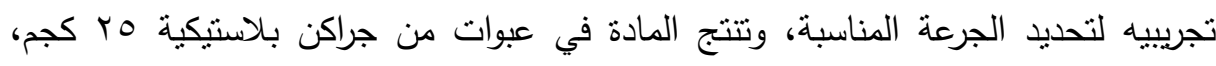

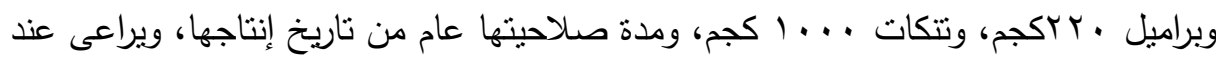
استخدامها الملابس الواقية منل القفازات والنظارات الواقية، وضرورة التهوية المناسبة في الأماكن المغلقة، وتجنب وجود أي مواد تساعد على الاشتعال بجانبها، وعدم التخلص من بقايا المادة في المجاري والمصارف المائية أو التربة.

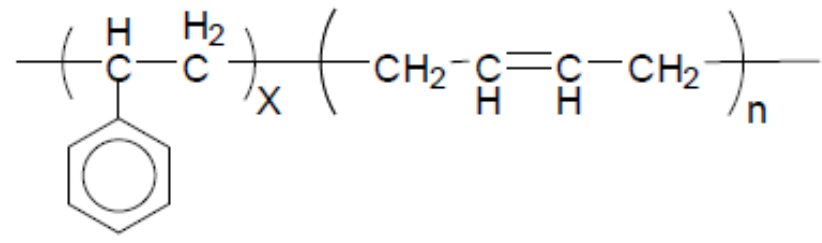

تعتبر مادة SBR (المستحلبة) من اللواصق المستخدمة في البناء لربط الأسمنت القديم

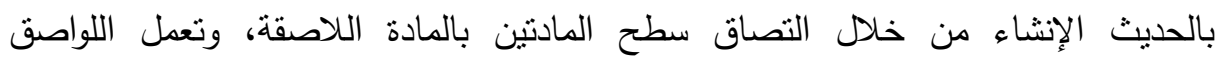

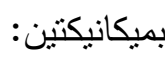
• التجاذب الفيزيائي بين السطح واللواصق. 
أبجاد محمد البصيري

• التفاعل الكيميائي بين اللواصق والسطوح مكوناً اتحاد كيميائي بين المادتين.

(C.V. Cagle, 1968: 108)

وتختلف اللواصق من حيث قوتها في درجات الحرارة المختلفة، ومدى مقاومتها للمواد

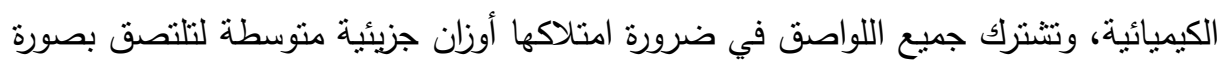

جيدة. (G. Michael \& A. Lrene, 1978 : 92

وتستخدم بعض هذه اللواصق (البوليمرية) لأغراض تحليلية وذلك لفصل وسحب بعض

الأيونات الثقيلة من المياه لتقليل التلوث البيئي الناتج من تلاه الأيونات.

(Zivicu, 1965: 121)

ويمكن تفسير سحب أيون الزئبق بواسطة SBR هو احتمالية حدوث تفاعل كيميائي بين

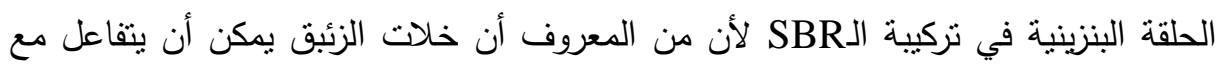

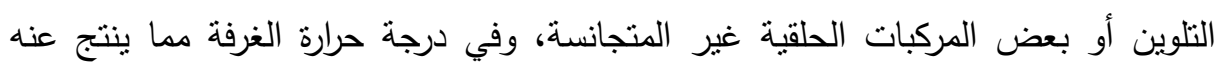

حدوث عملية الزئبقة على المركبات الاروماتية. (طلال أحمد، (ب.ت) :

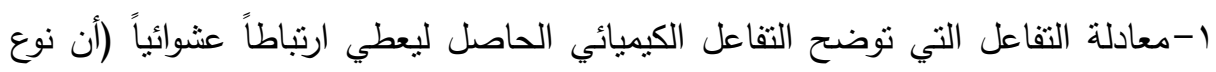
الكو بوليمر المضر من قبل هذه الشركة هو عشوائي Random. إضافة إلى ارتباط

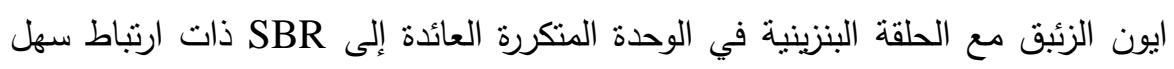

ومستقر جداً مقاوم إلى درجات عالية من الدالة الحامضية.

r-يتغلغل أيون الزئبق خلال الفراغات البينية في التركيبة الخرسانية.

r-إحلال ايون الزئيق خلال عملية الاماهة محل الكالسيوم والمغنيسيوم وخروجها كأملاح كليه

صلبة ذائبة (B. Palmer, 1999 : 33) (TDS) Total dissolved salts 
التجرية: قام الباحث بعمل واحد من الاختبارات الأساسية التي تتم على الخرسانة، وتعطي

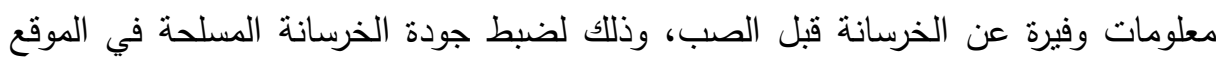

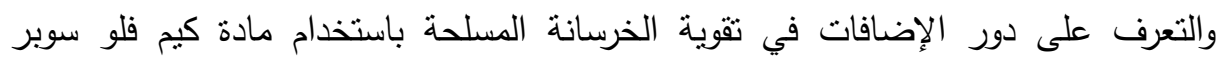
(CF/ACC) الأدوات المستخدمة في التجربة : • قالب معدني مخروط ناقص الثكل من الصاج المجلفن سمكه 1.5م وسطحه الداخلي ناعماً وخالياً من البروزات. • حوض مسطح: لتجهيز العينة ، وهو عبارة عن مسطح 1.2م * 1.2م سمك وعمق وفق

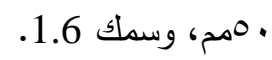
• قضيب للامك: يستخدم لدمك الخرسانة، وهو عبارة عن قضيب مستعرض مستدير بقطر 7 امم وطول • آسم، وبنهايتين كل منهما شباه كروية. • شريط مدرج: لقياس مسنوى هبوط الخرسانة.

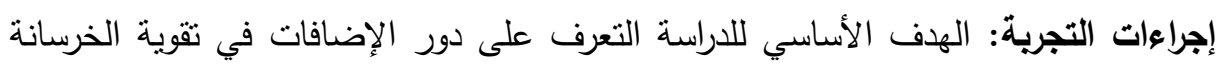

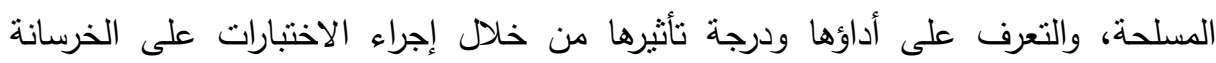

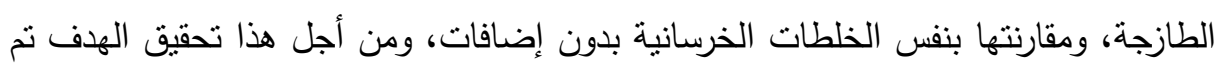
إجراء الاختبار على خلطتين بنفس المواصفات إحداهما بدون إضافات، وتسمى خلطة التحكم أما الخلطة الخرسانية الثانية يضاف لها المواد المراد اختبارها، وتنسى الخلطة التجريبية. أولاً : خلطة التحكم (بدون إضافات)على التحو التالي: المكونات المستخدمة في التجربة:

\begin{tabular}{|c|c|c|c|}
\hline ماء & زلط & رمل & أسمنت \\
\hline rالتر & rاكجم & גكجم & סكجم \\
\hline . . 5 & $\% r_{6} \varepsilon$ & $\% 1.7$ & $\% 1$ \\
\hline
\end{tabular}




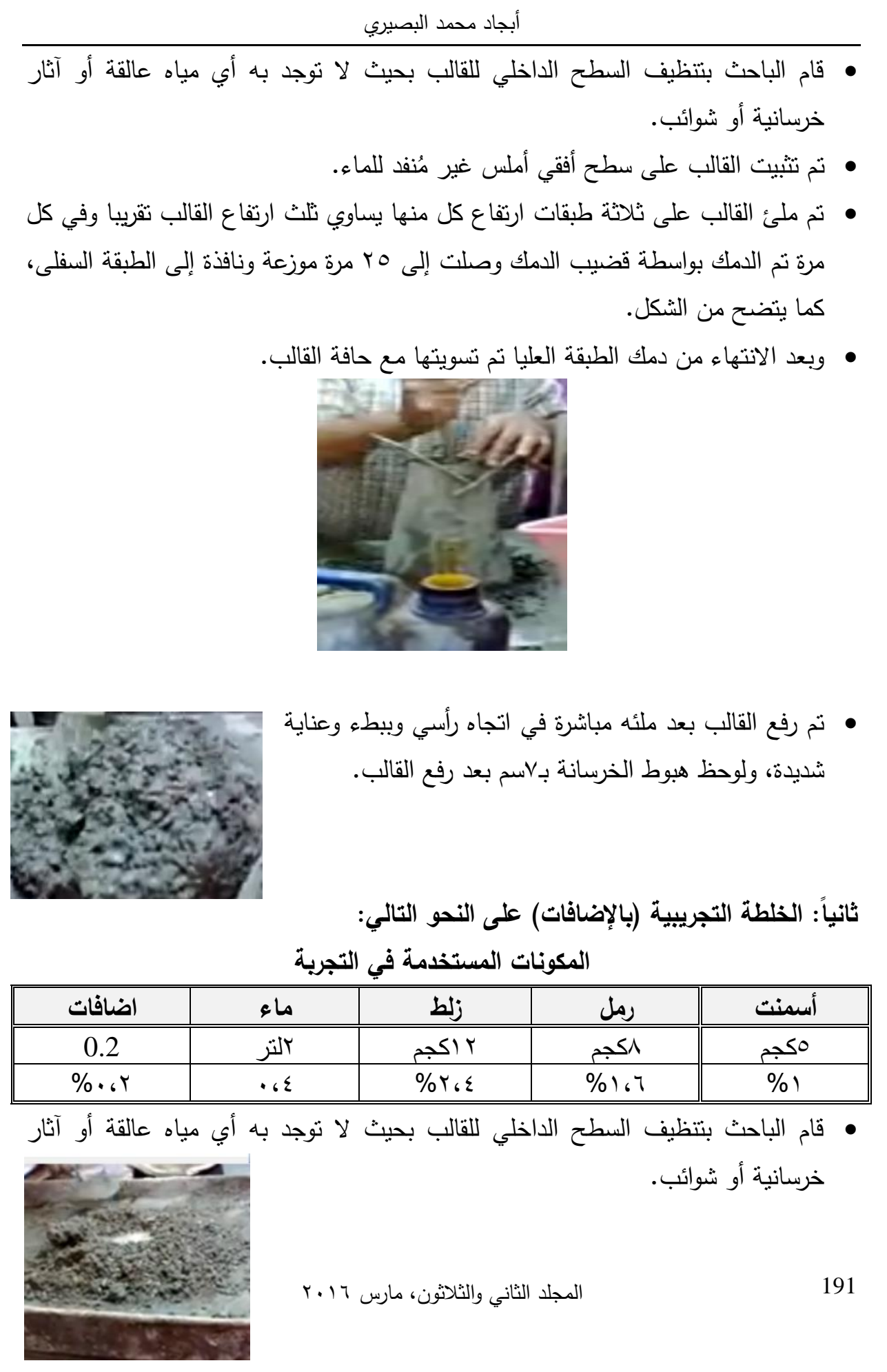


• تم تثبيت القالب على سطح أفقي أملس غير مُنفد للماء.

• ت تم وضع نفس المكونات بالخلطة السابقة (خلطة التحكم) + اضافة مادة كيم فلو سوبر .

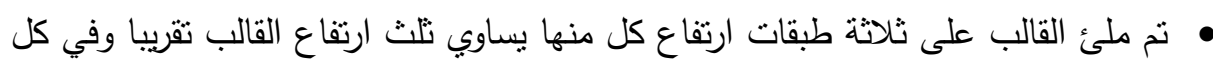

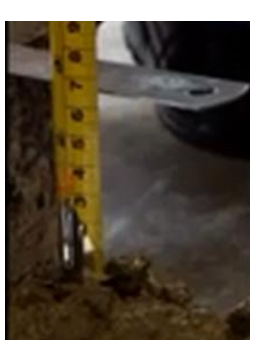
مرة تم الدمك بواسطة قضيب الدمك وصلت إلى مب مرة موزعة مركة ونافذة إلى الطبقة السفلى. • وبعد الاتتهاء من دمك الطبقة العليا تم تسويتها مع حافة القالب. • تم رفع القالب بعد ملئه مباشرة في اتجاه رأسي وبيطء وعناية شديدة، ولوحظ هبوط الخرسانة بـا سم بعد رفع القالب.

\section{نمأئ التراسما}

وتوصلت الدراسة للنتائج التالية: يتضح من خلال التجربة بين خلطة التحكم (بدون إضافات) هبوط الخرسانة = Vاسم،

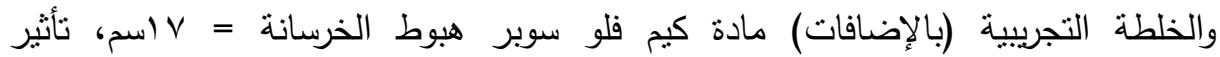
الإضافات على مستوى هبوط الخرسانة في الخلطة التجريبية، حيث أثنتت الإضافات فاعليتها في ثبات الخرسانة عند تطبيقها على خلطة التحكم (بدون إضافات).

\section{تموسياني السواسمة}

$$
\text { يوصي الباحث بالآتي: }
$$

• ضرورة استخدام الاضافات للخرسانة لما لها من دور فاعل في تقوية الخرسانة المسلحة. • يجب أن لا تخلط الإضافات في الخرسانة إلا بعد موافقة المهند المسئول عن المشروع. • تحديد المواد المناسبة للعمليات المطلوبة.

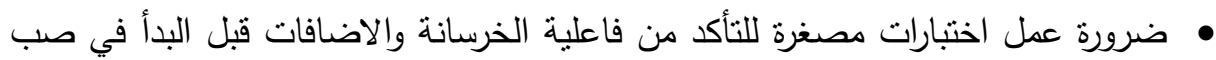
الخرسانة بالموقع. 
أبجاد محمد البصيري

\section{المرالئ2}

إبراهيم محمد أمين الثيخ (ع ( ـ Y): أسباب التصدعات والثـروخ بالمنشـآت الخرسانية وطرق

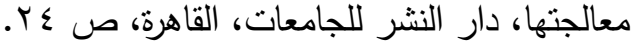

اتحاد المهندين العرب (9VV ()): الكود العربي لتصميم وتتفيذ المنشآت الخرسانية المسلحة،

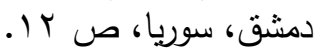

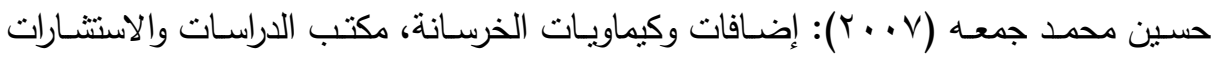

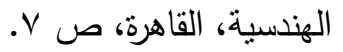

زهيـر سـاكو ، و أرتين ليفـون (19191): إنثـاء المبـاني ، دار الكتب للنشـر والتوزيـع، كليـة

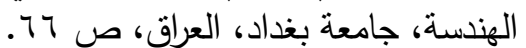

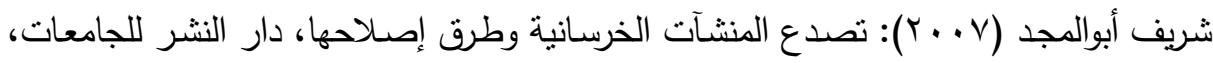

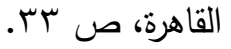

طلال أحمد (ب.ت): مبادئ في الكيمياء العضوية الفلزية، قسم الكيمياء، كلية العلوم، جامعة

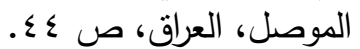

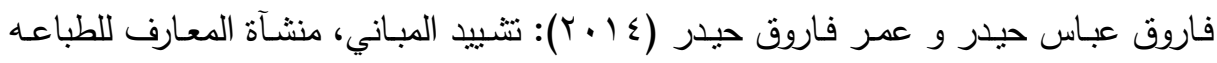

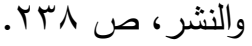

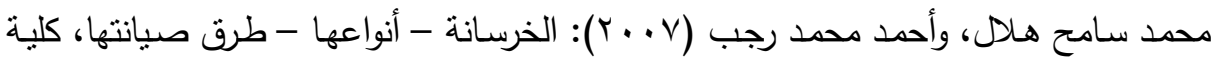

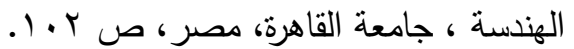

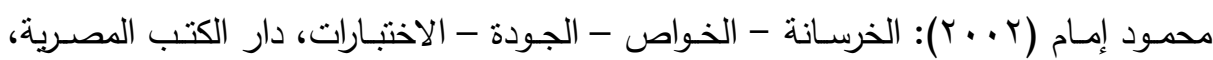

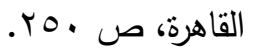

Brooks J J and Al-Quarra H (1999): Assessment Of Creep and Shrinkage For The Flintshire Bridge, The Structural Engineer, 77, 5, pp. 21-26.

Page. C. L. \& M. M. Page (2007): Durability of Concrete and Composites, Wood Head Publishing Limited, Cambridge England, PP. 1-220.

Cagle. C.V. (1968): "Adheisve Bonding" Technique and Application McGraw-Hill, Book Comp, New York, P. 108.

Michael. G. and A. Lrene (1978): AFormalary Of Paints and Other Coating, p. 79.

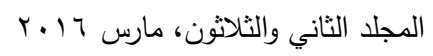


Taylor. H. F. W. (1997): Cement Chemistry, 2nd Edition, Thomas Telford Publishing, Ltd, London, PP. 2-5.

Hudson, B., (1997): Manufactured Sand: Destroying Some Myths," Quarry, October, PP. 58-63.

Michael P. Edison (2008) : Natural Cement, Library of Congress Cataloging In Publication Data, U.S.A., PP. 75-76.

Mindess, S. and Young, J. F.,(1981): Concrete , Printice-Hall. Inc Publish, P. 142.

Pedeferri P (1996): Cathodic Protection and Cathodic Prevention', Construction and Building Materials, 10 (5), pp. 391-402.

Pedro Nel Quiroga and David W. Fowler (2003): The Effects of Aggregates Characteristics on The Performance of Portland Cement Concrete, International Center For Aggregates Research, Aggregates Foundation for Technology, Research, and Education, U.S.A., PP. 98-122.

Prakem (2014): Speciality Chemicals, Product Data Sheet, Identification, No. Ca-5, https://www.ihs.com/products/specialtychemicals-industry-scup.html (4/12/2015)

Sadoon Morad (1998): Carbonate Cementation In Sandstones, The International Association of Sedimentologists, Blackwell Science Ltd., U.S.A, PP. 4-35.

Shilstone, J. M, Sr. and Shilstone, J. M., Jr., (2002): Performance-Based Concrete Mixtures and Specifications For Today, Concrete International, U.S.A., PP. 204-215.

Sommer, H., Nixon, P.J. and Sims, I. (2005): Aar-5: Rapid Preliminary Screening Test For Carbonate Aggregates', Materials and Structures, 38 (282), pp. 787-792..

Zivicu. V. (1965): The Properties of Cement Paste With Admixture of Poly-Vinyl Acetate Emulsion, No. 28, PP. 121-140.

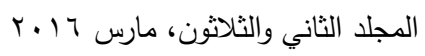


أبجاد محمد البصبري

Palmer. W.B. (1999): "Status And Estimated Life of Tanks" J. Enging.

Envir. Labor. No. (64), Vol. (15), p. 128.

\title{
THE ROLE OF SPECIAL ADDITIVES IN THE STRENGTHENING OF REINFORCED CONCRETE
}

\author{
El-Bosiery, A. M. \\ Education General Institute and Training in Kuwait
}

\begin{abstract}
The study aims to identify the role of the special additives for strengthening reinforced concrete used in construction, as the researcher presented the theoretical frameworks for the definition of reinforced concrete and its components as well as the special additives used in concrete, identifying its types and components.

The experimental method based on the experience was used to reach the role of special additives to strengthen reinforced concrete and the researcher performed an experiment using the substance $(\mathrm{CF} / \mathrm{ACC})$ in its liquid form.

The study reached the following:

Control batch (without additives), produced fresh concrete slump equals $7 \mathrm{~cm}$, and the experimental batch with additives (CF/ACC) produced fresh slump equals $7 \mathrm{~cm}$, the effect of additives on the level of concrete slump in the experimental batch, where the additives proved its effectiveness in concrete stability.

The study also recommended the following:

- The need to use the additives to the concrete because of its active role in enhancing the properties the reinforced concrete.

- The additives should not be mixed to the concrete except after the approval of the engineer who responsible for the project.

- Determine the appropriate materials for the required operations.
\end{abstract}

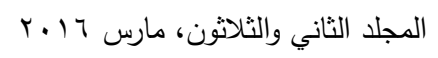


مجلة العلوم البيئية

معهد الدراسات والبحوث البيئية - جامعة عين شمس

- The need to make mini tests to make sure of the concrete and additives effectiveness before starting in casting the concrete in the site.

Key words: Special Additives+The Strengthening+Reinforced

Concrete 